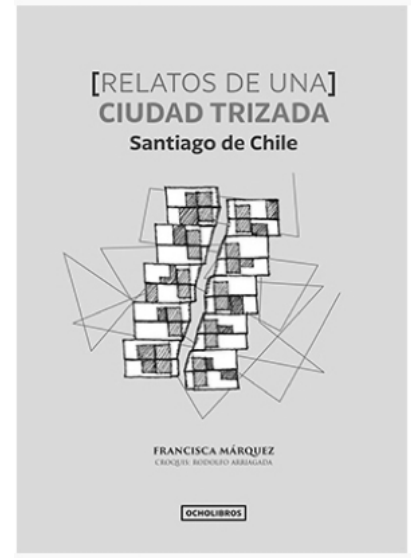

[Relatos de una] ciudad trizada es un intento de conceptualizar los modos de habitar en Santiago de Chile que recoge más de dos décadas de investigación de su autora, Francisca Márquez, una voz reconocida de la antropología urbana en Chile. La obra es la síntesis de un programa de investigación que plantea una lectura para comprender cómo los habitantes de Santiago se relacionan con sus barrios y con la ciudad. El texto toma la forma de una memoria personal, que en ocasiones se acerca al estilo de un cuaderno de campo etnográfico, mientras que en otras asume el carácter de un análisis arquitectónico y urbanístico. Tales aproximaciones se combinan para dar forma a un ensayo sólido que discute diferentes aristas conceptuales de la vida urbana y de los

\section{[RELATOS DE UNA] \\ CIUDAD TRIZADA \\ SANTIAGO DE CHILE}

\section{Francisca Márquez}

Santiago: Ocho Libros, 2017 (255 Pr.)

procesos de construcción de identidad, junto con entregar antecedentes de más de una decena de barrios de Santiago, con énfasis en los proyectos urbanos que les dan vida y sus transformaciones producto de las formas de vida que los ocupan. No obstante, el objetivo del libro es más ambicioso que proveer un conjunto de análisis de cada caso abordado. Se propone construir, tal como su título indica, un "relato" de la ciudad de Santiago, reconociendo la multiplicidad que en ella se da, pero dando cuenta a la vez de su articulación en una suerte de "espíritu del lugar", que contribuye a la construcción de un imaginario urbano. En efecto, el libro es una obra original en el contexto local, al integrar diferentes fuentes para la construcción de un relato que pone en el centro las percepciones 
y significaciones de los habitantes, pero, por sobre todo, sus afectos y emociones. Se puede decir que el propósito del libro es develar los afectos que vinculan a los habitantes entre sí y con la ciudad.

Los barrios de Santiago son el principal objeto de estudio de esta obra, que integra sus elementos físicos -a veces acompañados en su descripción por sugerentes croquis de Rodolfo Arriagada- y los discursos e historias que les dan existencia material, imbricados con descripciones que hablan de las formas en que sus habitantes se relacionan. En esta combinación, el libro se puede leer como uno de historia urbana, gracias a antecedentes novedosos en la concepción de determinados barrios; y a la vez como de antropología, en cuanto se vuelca a la pregunta respecto de cómo los habitantes se relacionan entre sí y con la materialidad y espacialidad de sus barrios.

La hipótesis que sostiene el relato de la ciudad se devela en las primeras páginas de la obra. La autora nos invita a mirar la ciudad de Santiago desde su propia experiencia: recoge en la introducción el descubrimiento, en su plena infancia, de la ciudad como espacio vivido y sońado el día mismo del bombardeo al Palacio de La Moneda el 11 de septiembre de 1973. De ese día, la autora comparte su observación de las columnas de humo que se levantan en el horizonte, imagen vicaria de una ciudad/sociedad que ha quebrado la posibilidad de construir un proyecto colectivo. Es el momento en que se triza la ciudad, se triza su comunidad. En el relato del libro, en los años posteriores al quiebre institucional, cada barrio y sus habitantes serán expresión y cuerpo de un creciente proceso de individuación cuyo correlato en la vida urbana se traduce en fragmentación, desolación, sumisión, temor, desarraigo, agobio, malestar, entre otras afectos y sentimientos de una ciudad que no logra restablecer un sentido colectivo. Esta es la base desde la cual la autora despliega una historia cultural de la ciudad de Santiago, propósito escasamente desarrollado hasta ahora para el caso de Santiago. Excepción a ello es La muralla enterrada (2001), ensayo del escritor Carlos Franz sobre la construcción literaria de Santiago, en cual -coincidentemente con Márquezdescribe una ciudad segregada y fragmentada, compuesta por conjuntos de habitantes que temen el encuentro con el otro. La diferencia entre ambos es que Franz, basado en numerosas obras literarias que transcurren en Santiago, plantea la trizadura de la ciudad desde principios del siglo xx como ethos de la ciudad de Santiago, mientras que Márquez, si bien lo reconoce, se basa en una investigación empírica cualitativa para dar un mayor énfasis a los efectos de la dictadura militar.

El libro está organizado a partir de cinco partes: Imaginarios, Identidades, Fronteras, Distinción y Márgenes. En la primera se plantea la importancia de los imaginarios como estrategias para organizar al interior de la ciudad lo similar entre sí, la diferencia, la desigualdad y alteridad. Los imaginarios, siempre en disputa, en el caso de Santiago habrían demarcado a través de la historia procesos de segregación y exclusión, expresados por la clásica distinción de Vicuńa Mackenna en el advenimiento de la ciudad moderna santiaguina entre ciudad letrada e iletrada, así como la ciudad vivida por los habitantes y la ideal trazada por los planificadores del siglo $\mathrm{xx}$. 
En la sección de Identidades se parte de la premisa según la cual la ciudad es un espacio de búsqueda permanente por reconstruir identidades, cuya base se ha visto cercenada por la experiencia del migrante rural en la urbe y que ha implicado una destrucción de la comunidad de origen. Esta distinción hace referencia a la tradición de sociedad versus comunidad trabajada tempranamente por la sociología urbana. En este contexto de desarraigo, la autora plantea que el barrio surge como el espacio central para la recomposición de las identidades colectivas, como oportunidad para reconfigurar las relaciones cara a cara y cotidianas que se han dejado atrás.

En la sección de Fronteras se aborda en específico la historia de La Chimba, como un barrio que ha acompañado buena parte de la historia urbana de Santiago en cuanto territorio "otro" que no se deja reducir a las categorías modernizadoras de la ciudad. La Chimba aparece como un espacio liminal, en transición, de acogida y expulsión, autogobernado y rebelde a las acciones racionalizadoras de la planificación urbana.

En la sección Distinción se recorre la historia de una decena de barrios, tales como Jardín del Este, Población San Gregorio, Torres de Tajamar, Villa Portales, entre otros, para dar cuenta de la forma en que cada uno de ellos expresó específicos proyectos político-urbanos. No obstante, más allá de la revisión histórica, es la experiencia actual de sus habitantes la que toma el centro de esta sección. En términos generales, se trata de experiencias que en la actualidad se encuentran lejos de los principios emancipatorios o de encuentro que originalmente los animaron.
En la sección Márgenes se abordan barrios de producción social del hábitat. Las historias de la población San Gregorio, del campamento El Resbalón y de Villa La Reina retratan el tesón colectivo por construir un hábitat digno, protagonizado por sus propios habitantes. El relato sobre estos espacios emblemáticos en la historia de las luchas por la vivienda de la segunda mitad del siglo xx va desde la organización colectiva al individualismo, desde el acompañamiento de diversas políticas públicas que vieron en estos esfuerzos un proceso ciudadano positivo para el país, al abandono y olvido actual.

Estas dos últimas secciones se desarrollan a través de breves y ágiles narraciones, las que permiten construir una compleja imagen de conjunto de la ciudad y dan vida a la parte más rica en términos empíricos y de análisis del libro. En ellas se propone leer lo metropolitano desde lo barrial (García Canclini, 2005). Siguiendo la estrategia predominante en la antropología urbana latinoamericana, Márquez aborda su desafío desde las microhistorias de los habitantes barriales, y de las relaciones que se construyen entre vecinos y las formas físicoespaciales -insertos en los discursos de la planificación ya sea formal o de producción social del hábitat- que dan vida a la arquitectura y urbanismo de los territorios de residencia. La base empírica de esta sección proviene de diferentes proyectos de investigación que la autora ha desarrollado en el transcurso de casi dos décadas.

El soporte teórico del libro remite a las corrientes de la antropología simbólica e interpretativa, así como de análisis de historia y teoría de la arquitectura y urbanismo. De estas fuentes, la ciudad 
es vista como un conjunto de discursos que se imbrican entre sí. Inspirado en la distinción trialéctica lefebvriana, el libro conjura discursos provenientes de los planificadores, de los habitantes y de sus disputas. Casi en todos los casos abordados en el libro, se trata de barrios construidos por un discurso moderno emancipatorio, con trazas reconocibles ya sea de los movimientos moderno de arquitectura, o de discursos políticorevolucionarios del siglo xx. Se trata de proyectos de ciudad que buscan, al menos en su formulación discursiva, la igualdad, la dignidad y la reivindicación. Por otra parte, se encuentran los habitantes cuyos relatos describen un repliegue desde la calle -de lo público y de la vecindad-, para recluirse en sus viviendas, en el imperio del espacio privado.

La última sección del libro, Epílogo, retorna sobre el quiebre entre esos relatos, quiebre que representa la trizadura del barrio y, en consecuencia, la imposibilidad de reconstrucción de las identidades colectivas en la ciudad.

Visto así, el libro logra su objetivo de explorar en relatos que permitan comprender la segregación, individuación y exclusión entre los habitantes. El resultado de todas estas narraciones se deja describir como desolación y desigualdad, como un malestar permanente en el ser habitante de Santiago.

El relato que nos propone Francisca Márquez para la ciudad de Santiago es, sin duda, uno de un proyecto fallido permanentemente. No obstante, se podría plantear que en la actualidad se desarrollan nuevas formas de asociatividad y resistencias cada vez más complejas. Es posible que en estas nuevas configuraciones el barrio pierda fuerza como unidad de sentido, mientras que surgen otras -especialmente lideradas por las generaciones jóvenes-, cuyas bases de vinculación se sostienen en nuevas territorialidades convocadas a través de redes sociales y comunidades de intereses especiales. Esto requiere de nuevas investigaciones empíricas que excede la empresa de esta obra.

Lo cierto es que el libro [Relatos de una] ciudad trizada está llamado a transformarse en un clásico de los estudios urbanos en Chile y de la reflexión cultural urbana en el ámbito latinoamericano. Y ello no solo por sus atractivas narraciones barriales o su debate teórico para definir lo urbano, sino también porque, hasta ahora, es de las pocas obras que se aventuran a construir una historia compleja de la ciudad de Santiago desde una mirada interdisciplinaria y con énfasis en las trayectorias de sus habitantes, entregando claves de interpretación para ser discutidas.

\section{Referencias bibliográficas}

García Canclini, N. (coord.). (2005). La antropología urbana en México. México, D.F.: Consejo Nacional para la Cultura y las Artes, Universidad Autónoma Metropolitana, Fondo de Cultura Económica.

Franz, C. (2001). La muralla enterrada. Bogotá: Planeta.

\section{Walter A. Imilan}

Universidad Central de Chile, Santiago, Chile.

E-MAIL: WALTER.IMILAN@UCENTRAL.CL 